\title{
РОЛЬ ВЗАИМОДЕЙСТВИЯ СЕМЬИ И ДОШКОЛЬНОЙ ОБРАЗОВАТЕЛЬНОЙ ОРГАНИЗАЦИИ В РАЗВИТИИ САМОСТОЯТЕЛЬНОСТИ ДОШКОЛЬНИКОВ
}

\section{Гогицаева О.У.}

За последнее время детская самостоятельность все чащие становится объектом внимания исследователей, преподавателей и педагогов. Проблеме самостоятельности посвящены работы Р.С. Буре, Т. Гуськова, В.Д. Иванов, И.С. Кон и др., рассматривающих самостоятельность как свойство личности, которое предполагает независимость, способность самостоятельно, без подсказки, принимать важные решения и проводить их в жизнь.

Самостоятельность развивается не только в семье, но и в условиях ДОО. Эффективности формирования самостоятельности у детей старшего дошкольного возраста будут способствовать следующие педагогические условия: челенаправленное формирование самостоятельности в семье с учетом уровня развития этого качества у ребенка; сотрудничество ДОО и семьи с иелью повышения уровня самостоятельности детей.

В ходе нашей исследовательской работы нами были выявлены особенности взаимодействия семьи и дошкольной образовательной организации в условиях реализачии ФГОС. Мы выяснили, что главной целлью в сотрудничестве с родителями является профессиональная помощь в вопросах воспитания и образования. При взаимодействии ДОО и родителей решаются задачи: активное взаимодействие с родителями для изучения их семейного микроклимата; оказание теоретической и практической помощи; повыпение общей культуры семьи и психолого-педагогической компетентности родителей; использование традиционных и нетрадиционных форм сотрудничества и творчества.

Нами были изучены методы, приемы и средства развития самостоятельности старших дошкольников в дошкольной организации 
и в семье: игры, проектная и поисковая деятельность, соблюдение режима дня, наличие домашних обязанностей, система поощрения и т.д. Проанализировав самостоятельность как качество личности дошкольника, мы пришли к выводу, что самостоятельность - это независимость, способность и стремление человека совершать действия или поступки без помощии других.

Ключевые слова: семья; дошкольники; самостоятельность; взаимодействие; педагогические условия; воспитание.

\section{THE ROLE OF INTERACTION \\ BETWEEN FAMILY AND PRESCHOOL EDUCATIONAL ORGANIZATION IN THE DEVELOPMENT OF INDEPENDENCE OF PRESCHOOLERS}

\section{Gogistaev O.U.}

In recent years, children's independence is increasingly becoming the object of attention of researchers, teachers and educators. The problem of independence is devoted to the work of R.S. Bure, T. Guskov, V.D. Ivanov, I.S. Kohn and others, who consider independence as a property of personality, which implies independence, the ability to independently, without prompting, make important decisions and implement them.

Independence develops not only in the family, but also in the preschool environment. The efficiency of formation of independence among children of senior preschool age will contribute to the following pedagogical conditions: targeted development of independence in the family given the level of development of this quality in the child; cooperation of the OED and families with the aim of increasing the level of autonomy of children.

In the course of our research work, we identified the features of interaction between the family and the preschool educational organization in the conditions of implementation of the GEF. We found that the main goal in cooperation with parents is professional assistance in matters of education and upbringing. At interaction of DOE and parents the 
tasks are solved: active interaction with parents for studying of their family microclimate; rendering theoretical and practical help; increase of the General culture of a family and psychological and pedagogical competence of parents; the use of traditional and non-traditional forms of cooperation and creativity.

We studied the methods, techniques and means of independence senior preschool children in preschool and the family: games, design and search activity, adherence of the day, the presence of household responsibilities, reward system, etc. after Analyzing autonomy as a quality of a preschooler, we came to the conclusion that independence is independence, the ability and willingness of a person to take actions or deeds without the help of others.

Keywords: family; preschoolers; independence; interaction; pedagogical conditions; education.

\section{Введение}

В Федеральном государственном образовательном стандарте дошкольного образования (ФГОС ДО) отмечается, для успешной социализации и индивидуализации дошкольников, необходимо создание психолого-педагогических условий, которые бы учитывали интересы и возможности всех детей; помогали поддерживать самостоятельность и инициативность детей в специфических для них видах деятельности; давали возможность выбора детьми видов активности, материалов, участников совместной деятельности и общения [9] . А для этого необходимо взаимодействие взрослых и детей в процессе образовательной деятельности. Сегодня большинство родителей испытывают трудности в воспитании детей изза занятости, нехватки времени, недостаточности компетентности в вопросах воспитания дошкольников. Задача дошкольной образовательной организации, в этой связи, дополнить, скорректировать семейное воспитание [3, 4, 5, 6, 8, 10, 13].

Как известно воспитание активной, самостоятельной, творческой личности возможно уже на этапе дошкольного детства. Анализ психолого-педагогической литературы показывает, что данный 
возрастной период благоприятен для формирования основ самостоятельности, о чем свидетельствуют работы А.В. Запорожец, А.Г. Ковалев, А.Н. Леонтьев, А.А. Люблинская, С.Л. Рубинштейн и др.

Исследование проблемы формирования самостоятельности осуществляется в разных аспектах. Изучается структура самостоятельности и соотношение ее компонентов (Ю.Н. Дмитриева, Г.Н. Година, Т.Г. Гуськова); сущность и природа самостоятельности дошкольника (Г.А. Балл, П.И. Пидкасистый, А.Г. Хрипкова); взаимосвязь самостоятельности с психическими процессами (Т.И. Горбатенко, Д.В. Ольшанский, Н.А. Цыркун); этапы, методы и условия развития самостоятельности (3.В. Елисеева, Н.С. Кривова, А.А. Люблинская, К.П. Кузовкова) [12].

Формы взаимодействия семьи и ДОО изучали Е.П. Арнаутов, Н.Ф. Виноградова, Л.С. Выготский, Г.Н. Година, В.М. Иванова, М.Д. Маханева, С. Мусиенко, Р.Ж. Мухамедрахимов, Н.И. Пирогов, Л.Н. Толстой, Д.Б. Филоновым и многие другие.

\section{Цель работы}

Исходя из вышеизложенного, наше исследование посвящено определению содержания и формы взаимодействия семьи и дошкольной образовательной организации в процессе развитии самостоятельности у старших дошкольников.

Цель исследования - теоретически обосновать развитие самостоятельности у старших дошкольников в процессе взаимодействия семьи и дошкольной образовательной организации, экспериментально проверить их содержание формы и определить эффективность.

Объект исследования - процесс взаимодействие семьи и дошкольной образовательной организации.

Предмет исследования - развитие самостоятельности старших дошкольников.

Гипотеза исследования: взаимодействие дошкольной образовательной организации и семьи в формировании самостоятельности у детей старшего дошкольного возраста будет эффективным, если: есть заинтересованность родителей; взаимодействие осуществля- 
ется на основе доверительных отношений между субъектами педагогического процесса;

\section{Методы и материалы исследования}

Методы исследования: теоретические - анализ научной психолого-педагогической и учебно-методической литературы; эмпирические - целенаправленное педагогическое наблюдение, опрос педагогов, анализ педагогической документации, беседы с детьми, формирующий педагогический эксперимент; математические - количественный и качественный анализ результатов исследования.

Как известно, качество дошкольного образования зависит от профессиональной компетентности педагогов и педагогической культуры родителей. Воспитатели и родители имеют единые задачи и цели: сделать так, чтобы дети росли здоровыми, общительными, активными, счастливыми, жизнелюбивыми, чтобы в будущем успешно они успешно учились в школе и реализовались как личности.

В соответствии с требованиями ФГОС ДО роль родителей в воспитании ребенка возрастает. Они становятся полноправными участниками образовательного процесса: участвуют в разработке и реализации программы, создании условий для своевременного и полноценного развития ребенка, в мероприятиях, которые проводятся в ДОО, в проектной деятельности.

Одна из основных задач ФГОС ДО - обеспечение психолого-педагогической поддержки семье и повышение компетентности родителей в вопросах образования и развития, охраны и укрепления здоровья детей.

В соответствии с ФГОС в обязанности детского сада входит: информирование родителей о целях дошкольного образования; открытость дошкольного образования; обеспечение вовлечения семей в образовательную деятельность, в том числе в создание образовательных проектов.

В процессе взаимодействия семьи и дошкольной организации за воспитание детей ответственны родители, а в задачи остальных социальных институтов входит помощь, поддержка, дополнение их воспитательной деятельности $[14,15]$. 
Анализируем имеющиеся трактовки понятия «взаимодействие», мы видим, что термин «взаимодействие» предполагает общение, обмен мыслями, чувствами, переживаниями.

В энциклопедическом словаре «взаимодействие»- это универсальная и объективная форма развития, движения, определяющая существование и структурную организацию любой материальной системы.

В психологии взаимодействие - это взаимное влияние психического и физического, души и тела.

\section{Результаты исследования и их обсуждение}

Целью взаимодействия является установление партнерских отношений между педагогом и родителями, их приобщение к жизни детского сада.

Задачи совместной работы ДОО и родителей: объединить усилия ДОО и семьи для воспитания и развития детей; установить партнерские отношения с семьями воспитанников; создать атмосферу взаимопонимания родителей и педагогов ДОО, эмоциональной взаимоподдержки и общности их интересов.

Основные направления совместной работы ДОО и родителей: изучение потребностей, мнений, запросов родителей в отношении качества образовательных услуг, которые предоставляет ДОО: анкетирование, социологические опросы, экспертные оценки, мониторинги и т.д.; психолого-педагогическое просвещение родителей; формирование в семье ценностей здорового образа жизни; управление образовательным процессом, образовательной организацией: участие в деятельности советов, материально-техническом обеспечении образовательного процесса, проектировании основной образовательной программы ДОО [11].

Работа с родителями - это процесс общения, который не всегда проходит гладко. Чаще всего возникают следующие проблемные ситуации: конфликты родителей из-за детей; жалобы педагогов на пассивность родителей; различные претензии родителей к воспитателям; непринятие родителями рекомендаций воспитателя из-за недостатка его авторитета [10]. 
Как видим, признание приоритета семейного воспитания требует новых взаимоотношений семьи и ДОО, они определяются понятием «взаимодействие». Цель такого взаимодействия - установление партнерских отношений между педагогом и родителями, их приобщение к жизни детского сада. Ведь от участия в работе ДОО родителей выигрывают каждый субъект педагогического процесса и особенно дети. Дошкольники узнают что-то новое, учатся с благодарностью, уважением и любовью смотреть на своих родных: педагоги могут лучше узнать семьи, понять слабые и сильные стороны домашнего воспитания, определить степень и характер своей помощи. Внедрение ФГОС позволяет более эффективно организовать совместную деятельность ДОО и семьи в этом направлении [9].

Самостоятельность дошкольников выражается в наличии у ребенка своего мнения, которое проявляется капризами, неподчинением или требовательностью.

Возраст 5-7 лет является сензитивным для развития способности к самостоятельному целеполаганию. Однако педагоги ДОО данную проблему не всегда учитывают в своей деятельности, отдавая предпочтение формированию у детей готовых, конкретных знаний, сами задают цель деятельности, выбирают пути и средства для ее достижения, что часто приводит к неумению дошкольников самостоятельно планировать деятельность, ставить цель, управлять своим поведением.

В 6-7 лет самостоятельность и инициатива проявляются намного тоньше и разнообразнее. Их самостоятельность проявляется в замысле и в развертывании сюжетов коллективных игр, в умении самостоятельно выполнить ответственное и трудное дело, которое было поручено группе. Возросшая самостоятельность сказывается и на умении оценивать работу и поведение остальных ребят [7].

Отличительная особенность самостоятельности старших дошкольников - ее организованность. Инициатива ребенка направлена на то, чтобы по-своему действовать, вопреки требованиям взрослых. Они могут направлять свою инициативу на то, чтобы быстрее и лучше выполнять порученное или задуманное ими дело в соответствии с требованиями взрослых. 
К показателям самостоятельности детей старшего дошкольного возраста можно отнести: стремление решать различные задачи без помощи окружающих, умение ставить цель деятельности, осуществить элементарное планирование, реализовать задуманное и получить адекватный поставленной цели результат, способность проявлять инициативу и творчество в решении возникающих задач $[1,2,3,6,11,16]$.

Таким образом, самостоятельность дошкольника можно понимать, как умение и стремление ребенка настойчиво решать задачи, относительно независимые от взрослого, мобилизуя знания, имеющийся опыт, используя поисковые действия.

Самостоятельность развивается не только в семье, но и в условиях ДОО. Эффективности формирования самостоятельности у детей старшего дошкольного возраста будут способствовать следующие педагогические условия: целенаправленное формирование самостоятельности в семье с учетом уровня развития этого качества у ребенка; сотрудничество ДОО и семьи с целью повышения уровня самостоятельности детей.

Наше исследование проводилось на базе ДОУ №3, города Владикавказ, в нем приняли участие дошкольники двух групп: контрольная группа 13 человек и экспериментальная - 11 человек.

Для проведения эксперимента нами были использованы: карта проявлений самостоятельности (А.М. Щетинина); анкетирование родителей «Что такое самостоятельность»; наблюдение (Методика Р.М. Геворкян «Особенности проявления воли дошкольников»).

На констатирующем этапе исследования нами были собраны первичные материалы, указывающие на наличие самостоятельности у детей старшего дошкольного возраста. Было отмечено, что большинство детей слабо владеют навыками самостоятельности. Также были зафиксированы результаты анкетирование родителей детей старшего возраста.

Результаты диагностики на констатирующем этапе стали базой для организации взаимодействия семьи и ДОО в развитии самостоятельности детей старшего дошкольного возраста.

В ходе проведения методики, было выявлено, что в группах преобладает низкий уровень самостоятельности, в первой группе 6 
респондентов, во второй 5. Такие дети чаще всего не имеют своей точки зрения, не умеют занять себя, или, не справляясь в какой-либо задачей, при возникновении конфликтов, сразу обращаются за помощью к взрослым или сверстникам, им легче работать в команде, а играть - в компании сверстников, чем самостоятельно, но даже в этом случае редко доводят до логического конца начатое дело. О порученных делах и своих обязанностях могут забывать, поэтому им нужен постоянный контроль со стороны педагога или родителей.

Средний уровень самостоятельности был выявлен у 4 детей первой группе и 4 детей во второй.

Высокий уровень был диагностирован у 3 дошкольников в первой группе и 2 у второй.

Далее мы посчитали целесообразным провести анкетирование родителей.

По итогам анкетирования можно сделать вывод, что с точки зрения родителей 10 детей находятся на низком, 9 на среднем, 5 на высоком уровне развития самостоятельности.

Родители детей с высоким уровнем самостоятельности стремятся воспитывать это качество в своих детях, так как считают, что самостоятельность для них очень важна. Дети, имеющие с точки зрения родителей высокий уровень самостоятельности, без контроля взрослых соблюдают режим дня, выполняют домашние обязанности, при выполнении заданий и поручений, начинают уверенно, выполняют их самостоятельно и правильно, не прибегая к помощи взрослых или делают это крайне редко и стараясь довести начатое дело до конца. Большинство таких детей могут играть в комнате за закрытой дверью и засыпать без ночника, умеют пользоваться телефоном и четко знают предел дозволенного. Играя в ролевые игры, дети в основном ставят себя на место взрослых, не проявляют садомазохистских наклонностей: понимают, когда больно и стараются избежать боли, не пытаются никому специально причинить боль. Они адекватно оценивают свои поступки.

Результаты проведения методики Р.М. Геворкян «Особенности проявления воли дошкольников» показали, что в двух группах старших дошкольников мало детей с высокими показателями сформированности 
показателей самостоятельности: по 1 человеку из двух групп имеют высокий уровень настойчивости и самостоятельности; по 2 человека - целеустремленности и инициативности, 3 человека - выдержки.

На среднем уровне развиты такие показатели: целеустремленность (у 5 человек из двух групп; настойчивость (у 10 детей); выдержка у 3 человек; решительность у 8 человек; самостоятельность у 7 человек ; инициативность у 5 человек.

Большая часть показателей имеет низкие значения: целеустремленность у 13 человек; настойчивость у 9 детей; выдержка у 14 человек; решительность у 11 человек; самостоятельность у 11 человек; инициативность у 10 человек.

На формирующем этапе исследования, нами было проведено повторное исследование, результаты которые были обработаны и проанализированы.

В ходе диагностики были использованы те же методики, что и на первом этапе исследования.

По итогам повторного анкетирования родителей в двух группах с количеством 24 человек, можно сделать вывод, что с точки зрения родителей у детей произошли изменения. На втором этапе 4 детей находятся на низком, 6 детей на среднем, 14 детей находятся на высоком уровне развития самостоятельности.

В повторном наблюдении за детьми по методике Р.М. Геворкян участвовало 24 человек, которые были участниками всех проводимых мероприятий, упомянутых выше.

По итогам наблюдения можно сделать вывод, что 5 ребёнка из одной группы и 3 из другой находятся на низком, 7 ребёнка одной группы и 6 второй группы на среднем, 11 ребёнка из одной группы и 3 из другой на высоком уровне развития самостоятельности.

\section{Заключение}

Полученные результаты свидетельствуют о том, что в данных группах произошли изменения.

Таким образом, можно утверждать, что целенаправленная работа в группах дошкольников, с педагогами и родителями способствует 
повышению самостоятельности у детей: самостоятельно выполнять доступные возрасту гигиенические процедуры и в детском саду и дома; без контроля взрослых соблюдать режим дня, выполнять домашние обязанности; иметь элементарные представления о необходимости соблюдения правил гигиены в повседневной жизни в детском саду и дома; при выполнении заданий и поручений, начинают уверенно, выполняют их самостоятельно и правильно, не прибегая к помощи взрослых или делают это крайне редко и стараясь довести начатое дело до конца.

\section{Список литературы}

1. Акулова Е.Ф. Формирование индивидуальности, самостоятельности и ответственности у дошкольников посредством подвижных игр // Наука, образование, общество. 2015. № 4 (6). С. 38-52.

2. Борисова О.Ф. Самостоятельность как база формирования социальных компетенций дошкольника // Детский сад от А до Я. 2015. №1. C. 124-132.

3. Волженина Т. Воспитание самостоятельности: советы родителям детей всех возрастов // Журнал «Виноград». 2014. № 37. С. 156.

4. Гогицаева О.У. Исследование ценностных ориентаций личности: ретроспективный аспект // Актуальные проблемы психолого-педагогического образования. Материалы международной научно-практической конференции. 2011. С. 70-77.

5. Гуриева С.Д. Семейные ценности и этническая идентичность в разных поколениях // Панорама Евразии. 2012. № 2 (10). С. 33-38.

6. Ежова Н.В. Работа с детьми и родителями в дошкольном образовательном учреждении. Ростов н/Д: Феникс, 2011. 282 с.

7. Качалова А.В., Каримов В.Р. Формирование самостоятельности детей старшего дошкольного возраста // Наука и школа. 2012. № 5. С. $112-114$.

8. К Кочисов Ч.В., Гогицаева О.У. Воспитательный потенциал осетинских традиций в этнокультурном развитии личности ребенка // Развитие регионов в ХХИ веке. Материалы И Международной научно практической конференции. Редактор: В.Г. Созанов. 2013. С. 386-392. 
9. Микерина А.С., Дедюкина М.И. Теоретическое обоснование проблемы формирования самостоятельности у детей дошкольного возраста // Вестник Челябинского государственного педагогического университета. 2016. № 5. С. 77-81.

10.Никифорова А.И. Компетентность родителей в воспитании самостоятельности у детей старшего дошкольного возраста // Научнометодический электронный журнал «Концепт». 2017. Т. 6. С. 60-62.

11. Никифорова Н.В., Баишева М.И. Формирование самостоятельности у детей старшего дошкольного возраста в условиях семьи // Научно-методический электронный журнал «Концепт». 2017. Т. 32. C. $169-171$.

12. Социальное партнёрство детского сада с родителями: сборник материалов/ Сост. Т.В. Цветкова. М.: ТЦ «Сфера», 2013. 133 ц.

13. Тарарухина О.В., Гуриева С.Д. Развитие методологии изучения межличностных отношений в социальной психологии // Вестник Северо-Осетинского государственного университета имени К. Л. Хетагурова. 2016. № 1. С. 101-107.

14. Фардзинова А.Р., Гогицаева О.У. Влияние детско-родительских отношений на самооценку подростка // Категория “социального” в современной педагогике и психологии. Материалы 6-й всероссийской научно-практической конференции с дистанционным и международным участием. 2018. С. 175-179.

15. Фардзинова А.Р., Гогицаева О.У. Межличностные отношения дошкольников в полиэтнической среде // Психология ХХИ века: психология как наука, искусство и призвание. Сборник научных трудов участников международной научной конференции молодых ученых: В двух томах. Под научной редакцией А.В. Шаболтас, С.Д. Гуриевой. 2018. С. 378-385.

16. Gogitsaeva O.U., Kochisov V.K., Shibzukhova D.A., Nebezheva A.V. Psychological conditions of interpersonal relationships formation of teenagers [The European Proceedings of Social \& Behavioural Sciences EpSBS Conference: SCTCGM 2018 - Social and Cultural Transformations in the Context of Modern Globalism. Conference Chair(s)], Groznyi, 2019. P. 2078-2086. 


\section{References}

1. Akulova E.F. Nauka, obrazovanie, obshchestvo. 2015. № 4 (6). P. 38-52.

2. Borisova O.F. Detskiy sad ot A do Ya. 2015. №1. P. 124-132.

3. Volzhenina T. Vinograd. 2014. № 37. P. 156.

4. Gogitsaeva O.U. Aktual'nye problemy psikhologo-pedagogicheskogo obrazovaniya. Materialy mezhdunarodnoy nauchno-prakticheskoy konferentsii [Actual problems of psychological and pedagogical education. Materials of the international scientific-practical conference]. 2011. P. 70-77.

5. Gurieva S.D. Panorama Evrazii. 2012. № 2 (10). P. 33-38.

6. Ezhova N.V. Rabota s det'mi i roditelyami $v$ doshkol'nom obrazovatel'nom uchrezhdenii [Work with children and parents in a preschool educational institution]. Rostov n/D: Feniks, 2011. 282 p.

7. Kachalova A.V., Karimov V.R. Nauka i shkola. 2012. № 5. P. 112-114.

8. Kochisov Ch.V., Gogitsaeva O.U. Razvitie regionov v KhKhI veke. Materialy I Mezhdunarodnoy nauchno prakticheskoy konferentsii [Regional development in the 21st century. Materials of the International Scientific and Practical Conference]. Ed. V.G. Sozanov. 2013. P. 386-392.

9. Mikerina A.S., Dedyukina M.I. Vestnik Chelyabinskogo gosudarstvennogo pedagogicheskogo universiteta. 2016. № 5. P. 77-81.

10. Nikiforova A.I. Kontsept. 2017. V. 6. P. 60-62.

11. Nikiforova N.V., Baisheva M.I. Kontsept. 2017. V. 32. P. 169-171.

12. Sotsial'noe partnerstvo detskogo sada s roditelyami: sbornik materialov [Social partnership of kindergarten with parents: collection of materials] sost. T.V. Tsvetkova. M.: TTs «Sfera», 2013. 133 ts.

13. Tararukhina O.V., Gurieva S.D. Vestnik Severo-Osetinskogo gosudarstvennogo universiteta imeni K. L. Khetagurova. 2016. № 1. P. 101-107.

14. Fardzinova A.R., Gogitsaeva O.U. Kategoriya "sotsial'nogo" v sovremennoy pedagogike i psikhologii. Materialy 6-y vserossiyskoy nauchno-prakticheskoy konferentsii s distantsionnym i mezhdunarodnym uchastiem [The category of "social" in modern pedagogy and psychology. Materials of the 6th All-Russian Scientific and Practical Conference with remote and international participation]. 2018. P. 175-179.

15. Fardzinova A.R., Gogitsaeva O.U. Psikhologiya KhKhI veka: psikhologiya kak nauka, iskusstvo i prizvanie. Sbornik nauchnykh trudov uchastnikov 
mezhdunarodnoy nauchnoy konferentsii molodykh uchenykh: V dvukh tomakh [Psychology of the XXI century: psychology as a science, art and vocation. Collection of scientific papers of participants in the international scientific conference of young scientists: In two volumes]. Ed. A.V. Shaboltas, S.D. Gurieva. 2018. S. 378-385.

16. Gogitsaeva O.U., Kochisov V.K., Shibzukhova D.A., Nebezheva A.V. Psychological conditions of interpersonal relationships formation of teenagers [The European Proceedings of Social \& Behavioural Sciences EpSBS Conference: SCTCGM 2018 - Social and Cultural Transformations in the Context of Modern Globalism. Conference Chair(s)], Groznyi, 2019. S. 2078-2086.

\section{ДАННЫЕ ОБ АВТОРЕ}

Гогицаева Ольга Урузбековна, к.пед.наук, доцент кафедры педагогики и психологии психолого-педагогического факультета Северо-Осетинского государственного университета им. К.Л. Хетагурова

ул. Ватутина, 44-46, Владикавказ, Респ. Северная ОсетияАлания, 362025, Российская Федерачия gogitsaeva@yandex.ru

\section{DATA ABOUT THE AUTHOR}

Gogitsaeva Olga Uruzbekovna, candidate of pedagogical sciences, assistant professor of psychology and pedagogy

North Ossetian State University

44-46, Vatutin Str., Vladikavkaz, North Ossetia-Alania, 362025, Russian Federation

gogitsaeva@yandex.ru

SPIN-code: 2628-5140

ORCID: 0000-0002-6893-7904 